\title{
Xanthogranulomatous pyelonephritis: a focus on microbiological and antibiotic resistance profiles
}

\author{
A. Artiles-Medina*, I. Laso-García, J. Lorca-Álvaro, M. Mata-Alcaraz, G. Duque-Ruiz, M. Hevia-Palacios, \\ F. Arias-Funez and F. J. Burgos-Revilla
}

\begin{abstract}
Background: Xanthogranulomatous pyelonephritis (XGP) is an inflammatory condition of the kidney and its treatment most often involves a combination of antibiotics and nephrectomy. This study aimed to define the clinical features and management of XGP, focusing on microbiological aspects and antibiotic therapy.

Methods: We performed a retrospective study of 27 cases of XGP diagnosed between January 2001 and January 2020 to analyse their clinical and management characteristics. In addition, a literature review was conducted of XGP case series covering the period from 2000-2020. We searched PubMed for case series through April 2020 without language restrictions. Studies reporting case series of XGP (more than ten cases) were included if they were relevant to this study.

Results: Twenty-seven patients were diagnosed with XGP, and 26 of them were histologically proven to have XGP. A total of $81.5 \%$ of the patients were female and the mean age was 59.6 years (SD 19.2). The most frequent symptoms were flank pain (70.4\%) and fever (59.3\%), while $77.8 \%$ of patients had renal stones. Proteus mirabilis was detected in the urine culture in $18.5 \%$ of patients, followed by detection of Escherichia coli in $14.8 \%$ of patients. The computed tomography (CT) findings included perirenal (29.6\%) or pararenal (29.6\%) involvement in the majority of patients. Twenty-six patients underwent nephrectomy. Piperacillin/tazobactam and ceftriaxone were the most commonly prescribed antibiotics for treatment. The reported piperacillin/tazobactam and ceftriaxone resistance rates were 14.3\% and 16.6\%, respectively. Twenty-six case series were included in the literature review, reporting 693 cases in total.

Conclusion: We found well-established characteristics of XGP patients among series in terms of previous history, clinical, laboratory and imaging findings, and operative and postoperative outcomes. It is important to know the clinical presentation and potential severity of XGP, as well as the most frequently involved microorganisms and their antibiotic resistance profiles, to select the most appropriate antibiotic therapy.
\end{abstract}

Keywords: Xanthogranulomatous pyelonephritis, Antibiotic resistance, Bacterial profile

\section{Background}

Xanthogranulomatous pyelonephritis (XGP) is an infrequent form of chronic granulomatous inflammation

*Correspondence: alberc.artiles@gmail.com

Department of Urology, Hospital Universitario Ramón Y Cajal. Instituto

Ramón Y Cajal de Investigación Sanitaria (IRYCIS), Madrid, Spain characterized by destruction of the renal parenchyma and replacement by solid sheets of lipid-laden macrophages. This rare entity constitutes less than $1 \%$ of chronic pyelonephritis [1]. The first case was reported by Schlagenhaufer in 1916. Because of diagnostic difficulties, relatively few cases have been published [2]. Since then, few series of cases (approximately 47 case series 
of at least ten reported cases) have been published, but there are no reviews compiling these series.

Escherichia coli and Proteus mirabilis are the isolated agents in approximately $90 \%$ of positive urinary cultures of XGP patients, although sterile urine cultures are not uncommon [3]. Generally, treatment of XGP includes antibiotic therapy and drainage of the abscess followed by nephrectomy for definitive treatment. Total nephrectomy (or in rare circumstances of focal XGP, partial nephrectomy) is the treatment of choice, and it is usually technically difficult due to extensive kidney adhesions to surrounding structures [4].

Antibiotics are used in all cases, but medical management only is rarely enough to solve the infection. Although surgery is regarded as the gold standard, antibiotic treatments have been proposed in children with unusual bilateral and focal XGP (with functioning kidney) [5]. In addition, symptomatic management through percutaneous drainage of abscesses can contribute to successful initial management of XGP.

Because XGP symptoms can be nonspecific, a diagnosis is often delayed, so imaging studies (ultrasound scan and computed tomography) are important in patients with recurrent or persistent pyelonephritis despite having been treated with adequate antibiotic therapy [6].

We report our case series (27 patients), focusing on fundamental, and yet insufficiently explored, microbiological and management aspects of XGP.

XGP can be a life-threatening condition; thus, data about culture isolates and antimicrobial resistances may guide antibiotic treatment in these cases. Our study contains antibiotics prescribed and antibiotic resistances identified in 27 cases of XGP, which are aspects not previously reported in the literature.

\section{Methods}

A review of discharge records from the urology department was conducted to identify patients with a diagnosis of XGP between January 2001 and January 2020 at our institution.

This is a retrospective cross-sectional study in which we collected data about clinical manifestations (symptoms and physical examination findings), risk factors, radiologic and laboratory (including microbiological) findings, and details of the management and the postoperative period. We analysed urine culture isolates, detected antibiotic resistance and used antimicrobial therapy. Our laboratory used a threshold of $10^{5} \mathrm{CFU} / \mathrm{ml}$ as a positive urine culture during the study period. Data sources were electronic medical records and nephrectomy specimens from the records of the Department of Pathology.
An extensive literature review was conducted of XGP case series covering the period from 2000 to 2020. This period was established to avoid biases due to diagnostic accuracy and management strategies; therefore, we selected only modern case series, similar to our series (2001-2020). The search strategy used in PubMed was as follows: "Pyelonephritis, Xanthogranulomatous"[Mesh] OR "Xanthogranulomatous Pyelonephritis"[Title/ abstract]. No language restriction was applied. Case series were included in the analysis if they reported more than ten cases and if they had information on the following variables (at least five): mean patient age, sex, risk factors (diabetes mellitus, immunosuppression, urolithiasis), clinical presentation, concomitant tumour, CT findings, main pathogens, prescribed antibiotics, nephrectomy approach and surgical complications.

\section{Results}

Between 2001 and 2020, 27 patients were diagnosed with XGP and 26 of them were histologically proven to have XGP (one patient refused nephrectomy). Table 1 shows

Table 1 Demographic characteristics and symptoms

\begin{tabular}{|c|c|}
\hline Variable & Value \\
\hline Age in years, mean (SD) & $59.6(19.2)$ \\
\hline Female vs male, $n(\%)$ & $22(81.5 \%)$ vs $5(18.5 \%)$ \\
\hline \multicolumn{2}{|l|}{ Side } \\
\hline Right kidney, n (\%) & $14(51.9 \%)$ \\
\hline Left kidney, n (\%) & $13(48.1)$ \\
\hline $\mathrm{DM}, \mathrm{n}(\%)$ & $3(11.1 \%)$ \\
\hline Immunosuppression, n (\%) & $2(7.4 \%)$ \\
\hline Concomitant renal tumour, n (\%) & $1(3.7 \%)$ \\
\hline Nephrolithiasis & $21(77.8 \%)$ \\
\hline Staghorn, n (\%) & $19(90 \%)$ \\
\hline Size in mm, mean (SD) & $23.5(4.7)$ \\
\hline \multicolumn{2}{|l|}{ Localization, n (\%) } \\
\hline Multiple & $17(81 \%)$ \\
\hline Renal pelvis & $3(14.3 \%)$ \\
\hline Upper calyx & $1(4.8 \%)$ \\
\hline Ureteric stones, n (\%) & $3(11.1 \%)$ \\
\hline Hydronephrosis, n (\%) & $17(63 \%)$ \\
\hline Recurrent urinary tract infections (UTI), $n$ (\%) & $9(33.3 \%)$ \\
\hline \multicolumn{2}{|l|}{ Clinical presentation } \\
\hline Acute debut, n (\%) & $17(63 \%)$ \\
\hline Renal mass, n (\%) & $7(25.9 \%)$ \\
\hline Gross hematuria, n (\%) & $1(3.7 \%)$ \\
\hline Flank pain, n (\%) & $19(70.4 \%)$ \\
\hline Constitutional syndrome, n (\%) & $3(11.1 \%)$ \\
\hline Weight loss, n (\%) & $3(11.1 \%)$ \\
\hline Fever, $\mathrm{n}(\%)$ & $16(59.3 \%)$ \\
\hline
\end{tabular}

DM: diabetes mellitus 
the patients' demographic characteristics and clinical presentation.

Table 2 summarizes the laboratory, radiologic and microbiological findings. Urine culture was positive in 13 cases (48.1\%). P. mirabilis was detected in the urine culture in $18.5 \%$ of patients, followed by detection of $E$. coli in $14.8 \%$ of patients. A mixed infection was detected in 2 patients $(7.4 \%)$.

The computed tomography (CT) findings included perirenal (29.6\%) or pararenal (29.6\%) involvement in the majority of patients and revealed a psoas abscess in three patients (11.1\%).

Table 2 Laboratory, radiologic and microbiological findings

\begin{tabular}{|c|c|}
\hline Variable & Value ( $\mathrm{n}$ and \%) \\
\hline \multicolumn{2}{|l|}{ Laboratory } \\
\hline \multicolumn{2}{|l|}{ Urine sediment } \\
\hline Pyuria, n (\%) & $7(25.9 \%)$ \\
\hline Microscopic hematuria, n (\%) & $3(11.1 \%)$ \\
\hline \multicolumn{2}{|l|}{ Blood tests } \\
\hline Hemoglobin in g/dL, mean (SD) & $10.1(S D$ 1.5) \\
\hline Serum creatinine in mg/dL, mean (SD) & $1.5(\mathrm{SD} 1.2)$ \\
\hline Estimated GFR in mL/min, mean (SD) & 62.01 (SD 27.39) \\
\hline WBC count per microliter, mean (SD) & $12,508.1(S D 4350.1)$ \\
\hline \multicolumn{2}{|l|}{ CT findings (M\&E classification) } \\
\hline Malek 1 & $10(37 \%)$ \\
\hline Malek 2 & $8(29.6 \%)$ \\
\hline Malek 3 & $8(29.6 \%)$ \\
\hline Psoas abscess & $3(11.1 \%)$ \\
\hline Positive urine culture & $13(48.1 \%)$ \\
\hline Proteus mirabilis & $5(18.5 \%)$ \\
\hline Escherichia coli & $4(14.8 \%)$ \\
\hline Pseudomonas aeruginosa & $2(7.4 \%)$ \\
\hline \multicolumn{2}{|l|}{ Mixed } \\
\hline E. coli+ Streptococcus constellatus & $1(3.7 \%)$ \\
\hline P. mirabilis + Serratia marcescens & $1(3.7 \%)$ \\
\hline \multicolumn{2}{|l|}{ Prescribed antibiotics } \\
\hline Piperacillin/tazobactam (TZP) & $13(48.1 \%)$ \\
\hline Ceftriaxone & $5(18.5 \%)$ \\
\hline Amoxicillin/clavulanic acid & $3(11.1 \%)$ \\
\hline Others & $6(21.9 \%)$ \\
\hline \multicolumn{2}{|l|}{ Overall antibiotic resistance profile (\%) } \\
\hline Quinolones & $14.30 \%$ \\
\hline Carbapenems & $0 \%$ \\
\hline Amoxicillin/clavulanic acid & $12.50 \%$ \\
\hline Piperacillin/tazobactam (TZP) & $14.30 \%$ \\
\hline Ceftriaxone & $16.60 \%$ \\
\hline Fosfomycin & $33.30 \%$ \\
\hline Trimethoprim/sulfamethoxazole (TMP/SMX) & $33.30 \%$ \\
\hline
\end{tabular}

GFR: glomerular filtration rate
Piperacillin/tazobactam (TZP) was the most commonly used antibiotic to treat XGP (48.1\%) and ceftriaxone, a third-generation cephalosporin, was the second most prescribed antibiotic (18.5\%). However, $14.3 \%$ of isolates exhibited some level of resistance to TZP and $16.6 \%$ were resistant to ceftriaxone.

Table 3 contains surgical data and postoperative complications of our case series. An open approach was used in $96.1 \%$ of the cases. Two patients had intestinal lesions and required a second operation (Clavien $3 \mathrm{~b}$ ). Two patients had septic shock and died in the early postoperative period (Clavien 5). Two patients needed blood transfusion and one patient had acute decompensated heart failure (Clavien 2). Another patient had a life-threatening pneumothorax that required drainage and ventilator support in the intensive care unit (Clavien $4 \mathrm{~b}$ ). Finally, surgical site infection was observed in 2 patients (Clavien 1 ). The overall complication rate was $38.5 \%$.

The supplementary table (see Additional file 1) summarizes case series between 2000 and 2020 [23-45]. Twenty-six case series met the inclusion criteria and were included, reporting 693 cases. Out of 26 case series, the most frequent isolate was $E$. coli in 8 of the series. After data extraction, we only identified one case series that reported the antibiotic prescribed.

\section{Discussion}

XGP is a rare, severe, chronic inflammatory condition of the kidney that leads to a nonfunctioning enlarged kidney and is normally associated with obstructive

Table 3 Surgical data and complications

\begin{tabular}{ll}
\hline Variable & Value (n and \%) \\
\hline $\begin{array}{l}\text { Nephrectomy, n (\%) } \\
\text { Approach }\end{array}$ & $26(96.3 \%)$ \\
$\quad$ Open & $25(96.1 \%)$ \\
$\quad$ Laparoscopic & $1(3.8 \%)$ \\
Type of procedure & \\
$\quad$ Urgent & $9(34.6 \%)$ \\
$\quad$ Elective or non-urgent & $17(65.4 \%)$ \\
Time-to-surgery in days (from clinical suspicious), & $38.2(54.5)$ \\
mean (SD) & \\
Postoperative complications (Clavien Dindo classifica- & $10(38.5 \%)$ \\
tion) & \\
Grado 1 & $2(20 \%)$ \\
Grado 2 & $3(30 \%)$ \\
Grado 3a & 0 \\
Grado 3b & $2(20 \%)$ \\
Grado 4 & $1(10 \%)$ \\
Grado 5 & $2(20 \%)$ \\
Overall mortality & $2(7.4 \%)$
\end{tabular}


uropathy secondary to nephrolithiasis [7]. This entity is increasingly well recognized and its confirmatory diagnosis is based on histopathological examination [1]. Only a few case series have been published.

XGP, a so-called "inflammatory tumour" of the kidney, involves the calyces, renal parenchyma and renal sinus areas, and it may spread into the perinephric tissue with the formation of abscesses and even fistulas [8] (Fig. 1). Its pathogenesis remains unclear, although it seems that bacterial infection and urinary obstruction are important factors in its pathophysiology. Histologically, xanthogranulomatous pyelonephritis consists of a granulomatous inflammatory infiltrate composed of neutrophils, lymphocytes, plasma cells, xanthomatous histiocytes, and multinucleated giant cells [9].

A correct preoperative diagnosis of XGP is very difficult because this entity can mimic other disorders, such as renal neoplasms (including clear cell renal cell carcinoma, papillary renal cell carcinoma, sarcomatoid renal cell carcinoma, leiomyosarcoma, Wilms tumour), chronic pyelonephritis, nephrolithiasis, tuberculosis, malakoplakia and megalocytic interstitial nephritis. It is well known that preoperative diagnosis of XGP is difficult, but high-resolution imaging techniques have enhanced diagnostic accuracy [10]. Studies have reported that a preoperative diagnosis can be achieved through a combination of clinical and radiologic data in

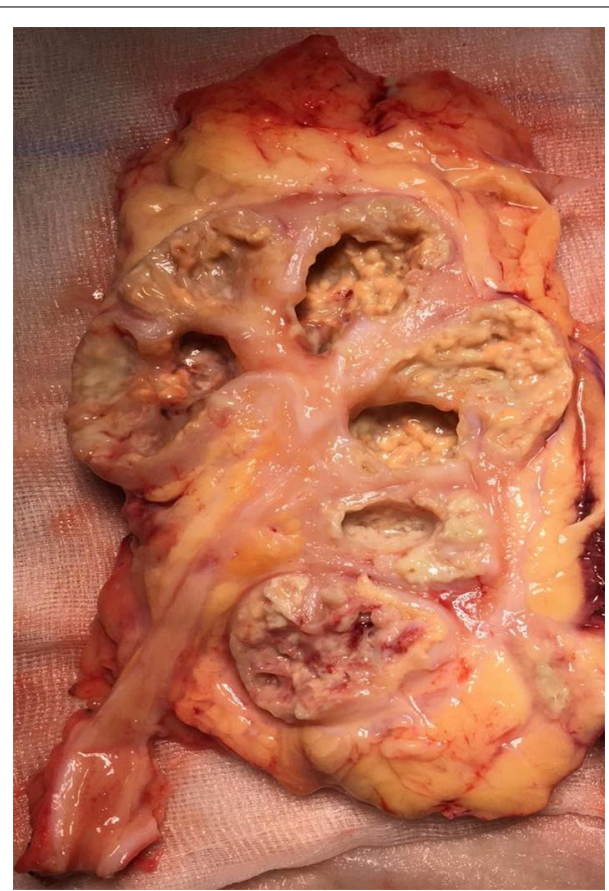

Fig. 1 Gross examination shows enlarged kidney and yellow nodules in the renal parenchyma only $40 \%$ of cases [11]. Generally, this chronic inflammatory process is unilateral, most frequently affects middle-aged women, and occasionally manifests in childhood.

Symptoms include flank pain, weight loss, and fever. Regarding clinical presentation, $\mathrm{Al}-\mathrm{Gh}$ azo et al. reported a series of 18 cases and noted that the clinical characteristics of XGP included calculi or obstruction in the urinary tract, damage to the kidney, complications of urinary tract infection, anaemia and increased erythrocyte sedimentation rate. Extended infections, such as psoas abscess, nephrocutaneous fistula, renocolonic fistula and paranephric abscess, can be found in the third group of cases [12]. Similarly, in our retrospective study, the computed tomography (CT) findings included perirenal $(29.6 \%)$ or pararenal $(29.6 \%)$ involvement in the majority of patients and a psoas abscess in three cases (11.1\%).

Kundu et al. conducted a 13-year retrospective study (2005-2017) to describe the clinicopathologic spectrum of XGP. This author described forty cases of XGP and reported diffuse renal parenchymal involvement in the majority of patients (77.5\%) and a high rate $(90 \%)$ of nephrolithiasis. Furthermore, in their series, these authors identified $5 \%$ of coexisting renal cell carcinomas in the same kidney [13]. In our case series, we found a nephrolithiasis rate of $77.8 \%$ and only one patient presented with concomitant renal cell carcinoma (3.7\%).

Based on published cases, the characteristics of our series are similar to those that have been previously reported.

Computed tomography is the mainstay of diagnostic imaging for xanthogranulomatous pyelonephritis. Eastham et al. retrospectively reviewed all medical records, including radiographic materials, of 27 patients with a pathologic diagnosis of XGP and reported an accuracy of $87 \%$ for CT scans for the preoperative diagnosis of XGP. CT accurately defined the extent of the perinephric inflammatory reaction [14]. According to Malek and Elder's radiological classification, XGP can be subdivided into 3 stages on the basis of the extent of involvement of the adjacent tissue [15]: stage I, nephric disease confined to the kidney; stage II, infiltration into the Gerota fascia; and stage III, disease extending into adjacent perinephric space and other retroperitoneal structures (Fig. 2) [16].

There are scarce data on antibiotic treatment used in XGP. It has been reported that one-third of patients have sterile urine and one-fourth have mixed growth in urine culture. The most frequent microorganisms isolated in urine culture are $P$. mirabilis, followed by $E$. coli. In the study of Dwivedi et al., these microorganisms were isolated in $23 \%$ and $11.5 \%$ of cases, respectively [7]. 

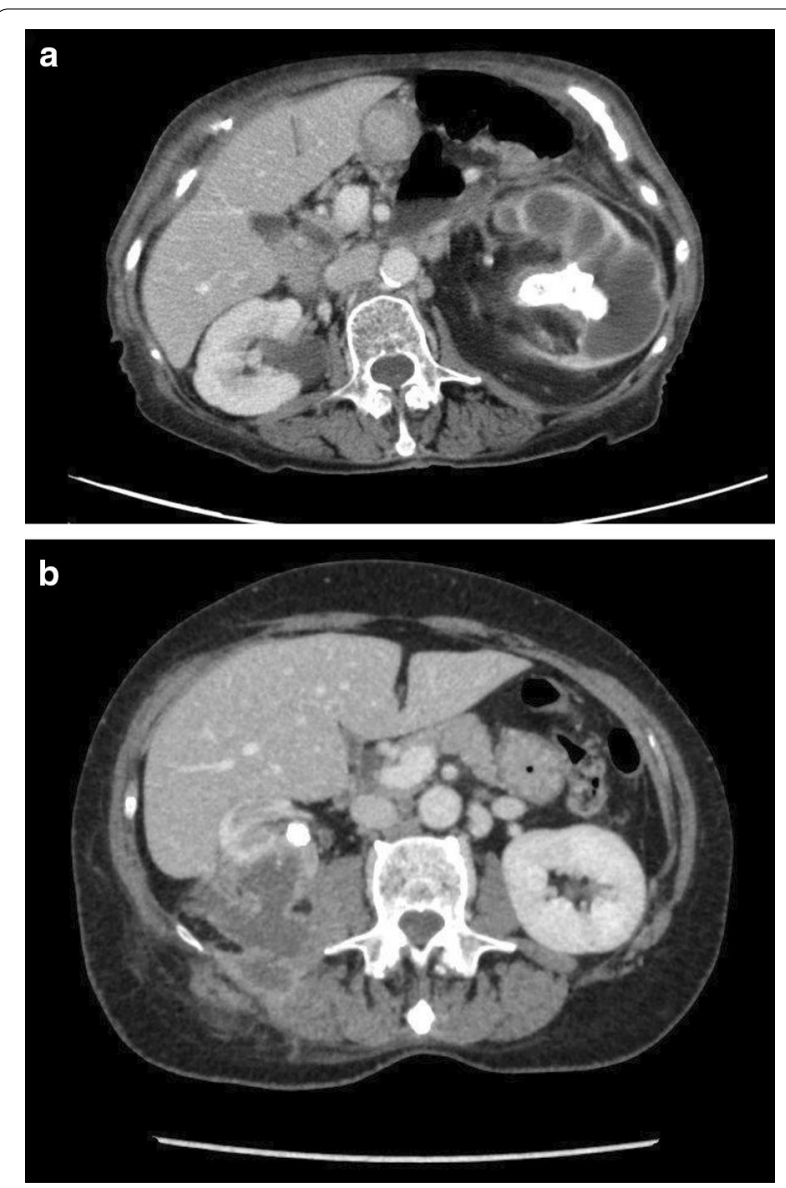

Fig. 2 Axial CT scan images demonstrate obstructing left pelvic staghorn stone with associated grade IV hydronephrosis (Malek I) (a) and retroperitoneal collections surrounding the right kidney with a renal pelvic calculus (Malek III) (b)

Petca et al. conducted a retrospective observational study from January 2013 to December 2017 that identified 29 patients diagnosed with XGP, of which 18 patients (62.06\%) showed a positive urine culture. In 16 out of the 18 cases with positive urine culture, a gram-negative microorganism from the Enterobacteriaceae family was isolated, while gram-positive microorganisms were detected in only two cases (6.89\%). Moreover, they reported that the microorganism most commonly identified was E. coli, followed by Proteus, Klebsiella, Enterococcus and Staphylococcus [17]. Consistent with this author, we reported a positive urine culture rate of $48.1 \%$. However, in our study $P$. mirabilis was the most common microorganism detected and was found in the urine culture in $18.5 \%$ of patients, followed by detection of E. coli in $14.8 \%$ of patients. A mixed infection was detected in 2 patients (Table 2).

Conservative management of XGP (with antibiotics or partial nephrectomy) has been described for focal forms of the disease. Nevertheless, diffuse forms usually require total nephrectomy [18]. As recommended by Schlossberg et al., extended-spectrum penicillin (e.g., piperacillintazobactam), cephalosporin (ceftriaxone or cefotaxime), fluoroquinolone (ciprofloxacin) or ampicillin with gentamicin are all appropriate choices for treatment. Intravenous treatment for 24-48 h after resolution of symptoms and fever is necessary, followed by at least 2 weeks of oral antibiotics based on susceptibility testing [19]. In our case series, piperacillin-tazobactam (48.1\%) and ceftriaxone $(18.5 \%)$ were the most frequent antibiotic therapies.

Considering increasing antibiotic resistance rates over the last decades, antibiotic therapy recommendations and prescribing patterns for acute pyelonephritis have changed. Enterobacteriaceae are common uropathogens causing acute pyelonephritis (APN), and $E$. coli is the most frequent among them. These uropathogens have become resistant to several important antibiotics, such as trimethoprim/sulfamethoxazole, fluoroquinolones (FQs) and $3^{\text {rd }}$ generation cephalosporins $\left(3^{\text {rd }}\right.$ CEPs). According to a study conducted in Korea by Kim et al., $3^{\text {rd }}$ CEPs were the most commonly prescribed antibiotics (41.4\%) for inpatients, followed by FQs. However, the use of $3^{\text {rd }}$ CEPs, beta-lactam/betalactamase inhibitors, and carbapenems increased substantially for the treatment of hospitalized APN patients. In particular, carbapenem use increased 3.1-fold over 5 years [20]. Moreover, the Study for Monitoring Antimicrobial Resistance Trends (SMART), which has collected 1,116 gram-negative urinary pathogens from hospitalized patients in 33 countries during 2009-2010, showed that the rates of fluoroquinolone resistance (FQR) in gramnegative bacilli vary widely country to country; for example, they were 23.5\% in North America, 29.4\% in Europe, and $33.2 \%$ in Asia. As a consequence, this study suggests that FQs may no longer be effective as first-line therapy for gram-negative UTIs in hospitalized patients [21].

The use of the laparoscopic approach for surgical treatment of XGP is controversial, but according to published case series, it can be successfully performed. Nevertheless, a high conversion rate (approximately 27\%) has been reported [4]. According to Khaira et al., laparoscopic nephrectomy in patients with XGP is often challenging and requires considerable experience in laparoscopy [22]. These authors reported grade 2 (Clavien-Dindo) complications in $40 \%$ and $29.4 \%$ of patients in the open and laparoscopic nephrectomy groups, respectively. In our study, the postoperative complication rate was $38.5 \%$ (grades $1-2$ in $50 \%$ of complications).

Regarding the strengths and limitations of this study, we were able to include 27 patients diagnosed with a very rare disease. Our findings were consistent with prior studies. We were also able to analyse 
microbiological aspects, such as antibiotic resistance and antibiotic therapies, that are very relevant in this infectious process but they have been insufficiently addressed in the literature. Nevertheless, in our data set, there were some variables with missing values, as well as incomplete data for some patients.

\section{Conclusions}

Xanthogranulomatous pyelonephritis is a rare entity, and its management usually involves antibiotics and total nephrectomy and occasionally drainage of abscesses. It is important to know its clinical presentation and potential severity, as well as the most frequently involved microorganisms and their antibiotic resistance profile, to select the most appropriate antibiotic therapy.

The literature review shows well-established characteristics of XGP patients among series in terms of previous history, clinical, laboratory and imaging findings, and operative and postoperative outcomes.

\section{Abbreviations}

CT: Computed tomography; DM: Diabetes mellitus; ID: Immunodeficiency; LN: Laparoscopic nephrectomy; ON: Open nephrectomy; XGP: xanthogranulomatous Pyelonephritis.

\section{Supplementary Information}

The online version contains supplementary material available at https://doi. org/10.1186/s12894-021-00800-z.

Additional file 1. Supplementary table: Case series of XGP (more than 10 cases).

\section{Acknowledgements}

Dr. Artiles Medina would like to thank Dr. Laso García and Dr. Lorca Álvaro for their help and previous work. They have encouraged me to develop this research.

\section{Authors' contributions}

All authors read and approved the final manuscript. Study design: AAM; ILG; FJBR. Data acquisition and analysis: AAM; ILG; JLA; MMA. Drafting manuscript: AAM; ILG. Critical revision of manuscript: ILG; GDR; MHP; FAF; FJBR.

\section{Funding}

This study did not receive any specific funding.

\section{Availability of data and materials}

The datasets will be available from the corresponding author upon reasonable request.

\section{Ethics approval and consent to participate}

This research is retrospective and involves the collection of existing data and records. All procedures performed in studies involving human participants were in accordance with the ethical standards of the institutional and/or national research committee(s) and with the Helsinki Declaration. The ethical committee of Hospital Ramón y Cajal of Madrid approved all procedures of the study and provided a waiver for the written informed consent.
Consent for publication

Not applicable.

\section{Competing interests}

The authors have no conflicts of interest to declare.

Received: 3 November 2020 Accepted: 17 February 2021

Published online: 07 April 2021

References

1. Yoshino, Moriyam H. Case of the diffuse form of xanthogranulomatous pyelonephritis. Case Rep Urol. 2013, Article ID 936035.

2. Nishimura M, Arai E, Katamura E. Xanthogranulomatous pyelonephritis: clinical experience of 8 cases. Hinyokika Kiyo. 1988;34(7):1211-6.

3. Titus B, Gupta S, Edpao P, Psutka SP, Limaye AP, Bakthavatsalam R, et al. Xanthogranulomatous pyelonephritis with direct extension into the liver. Am J Med. Elsevier Inc.; 2020.

4. Pastore V, Niglio F, Basile A, Cocomazzi R, Faticato MG, Aceto G, et al. Laparascopic-assisted nephroureterectomy for shaped urolithiasis and xanthogranulomatous pyelonephritis: case report and review of literature. Afr J Paediatr Surg. 2013;10(3):285-8.

5. Gupta S, Araya CE, Dharnidharka VR. Xanthogranulomatous pyelonephritis in pediatric patients: case report and review of literature. J Pediatr Urol. 2010;6(4):355-8.

6. Oostergo T, Rietbergen JBW, Schrama YC. Refractory urinary tract infections: diagnosis and treatment of xanthogranulomatous pyelonephritis. Ned Tijdschr Geneeskd. 2013;157(11):A5328.

7. Dwivedi US, Goyal NK, Saxena V, Acharya RL, Trivedi S, Singh PB, et al. Xanthogranulomatous pyelonephritis: our experience with review of published reports. ANZ J Surg. 2006;76(11):1007-9.

8. Mittal BV, Badhe BP. Xanthogranulomatous pyelonephritis-(a clinicopathological study of 15 cases). J Postgrad Med. 1989;35(4):209-14.

9. Li L, Parwani AV. Xanthogranulomatous pyelonephritis. Arch Pathol Lab Med. 2011;135(5):671-4.

10. Paez Borda A, Silmi A, Diego A, Prieto L, Gómez J, Blázquez J, et al. Xanthogranulomatous pyelonephritis. Retrospect Stud Arch Esp Urol. 1990:43(8):843-9.

11. Xanthogranulomatous Pyelonephritis - an overview | ScienceDirect Topics [Internet]. [cited 2020 May 31]. https://www.sciencedirect.com/topics/ medicine-and-dentistry/xanthogranulomatous-pyelonephritis

12. Al-Ghazo MA, Ghalayini IF, Matalka II, Al-Kaisi NS, Khader YS. Xanthogranulomatous pyelonephritis: Analysis of 18 cases. Asian J Surg. 2006;29(4):257-61.

13. Kundu R, Baliyan A, Dhingra H, Bhalla V, Punia RS. Clinicopathological spectrum of xanthogranulomatous pyelonephritis. Indian J Nephrol. 2019:29(2):111-5.

14. Eastham J, Ahlering T, Skinner E. Xanthogranulomatous pyelonephritis: clinical findings and surgical considerations. Urology. 1994;43(3):295-9.

15. Ballentine WK 3rd, Vilson F, Dyer RB, Mirzazadeh M. Nephron-sparing management of Xanthogranulomatous pyelonephritis presenting as spontaneous renal hemorrhage: a case report and literature review. BMC Urol. 2018;18(1):57.

16. Banerjee I, Tomar V, Yadav SS, Vyas N, Talreja S. Xanthogranulomatous pyeIonephritis presenting as a type IV renal cyst. Rev Urol. 2017;19(1):60-3.

17. Petca R, Popescu R, Mares C, Mehedintu C, Mastalier B, Badiu D, et al. Xanthogranulomatous pyelonephritis: presentation and management. J Mind Med Sci. 2019;169-75.

18. Xanthogranulomatous pyelonephritis presenting as Proteus preperitoneal abscess|Journal of Surgical Case Reports | Oxford Academic [Internet]. [cited 2020 Jun 8]. https://academic.oup.com/jscr/article/2016/ 12/rjw211/2631151

19. Schlossberg D. Clinical infectious disease, second edition [Internet]. Clinical Infectious Disease, Second Edition. Cambridge University Press; 2015 [cited 2020 Jun 23]. 1-1470 p. /core/books/clinical-infectious-disease/ C6BD638850420DD0794483168E1078AF 
20. Kim B, Myung R, Lee MJ, Kim J, Pai H. Trend of antibiotics usage for acute pyelonephritis in Korea based on national health insurance data 2010-2014. BMC Infect Dis BioMed Central Ltd. 2019;19:554.

21. Bouchillon S. Fluoroquinolone resistance among gram-negative urinary tract patho-gens: global smart program results, 2009-2010. Open Microbiol J. 2012;6(1):74-8.

22. Khaira HS, Shah RB, Wolf JSJ. Laparoscopic and open surgical nephrectomy for xanthogranulomatous pyelonephritis. J Endourol. 2005:19(7):813-7.

23. Campanario-Pérez R, Sáiz-Marenco R, Amores-Bermúdez J, Arroyo-Maestre JM, Quintero-Gómez V, Ruíz-Rosety E, et al. Laparoscopic nephrectomy for the management of xanthogranulomatous pyelonephritis: still a challenging procedure. J Endourol. 2018;32(9):859-64.

24. Ichaoui H, Saadi A, Chakroun M, Ayed H, Bouzouita A, Cherif M, et al. Xanthogranulomatous pyelonephritis in adults: clinical, biological, radiological and therapeutic main findings in diffuse and focal forms. About 42 cases. Tunis Med. 2018;96(8-9):495-500.

25. Stoica I, O'Kelly F, McDermott MB, Quinn FMJ. Xanthogranulomatous pyelonephritis in a paediatric cohort (1963-2016): Outcomes from a large single-center series. J Pediatr Urol. 2018;14(2):169.e1-169.e7.

26. Çaliskan S, Özsoy E, Kaba S, Koca O, Öztürk MI. Xanthogranulomatous pyelonephritis. Arch Iran Med. 2016;19(10):712-4.

27. Addison B, Zargar H, Lilic N, Merrilees D, Rice M. Analysis of 35 cases of xanthogranulomatous pyelonephritis. ANZ J Surg. 2015;85(3):150-3.

28. Datta B, Datta C, Pahari DK. Xanthogranulomatous pyelonephritis: critical analysis of 18 cases from a rural tertiary care centre of India. J Indian Med Assoc. 2014;112(1):33-5.

29. Kim SW, Yoon B II, Ha U-S, Sohn DW, Cho Y-H. Xanthogranulomatous pyelonephritis: clinical experience with 21 cases. J Infect Chemother Off J Japan Soc Chemother. 2013;19(6):1221-4.

30. Nam JK, Park SW, Lee SD, Chung MK. Xanthogranulomatous pyelonephritis in Korean children. Yonsei Med J. 2012;53(6):1159-64.

31. Lima M, Miyaoka R, Moro J, D'Ancona C. Laparoscopic nephrectomy for xanthogranulomatous pyelonephritis-are there predictive factors for success? Clin (Sao Paulo). 2012;67(8):907-9.

32. Kuo C-C, Wu C-F, Huang C-C, Lee Y-J, Lin W-C, Tsai C-W, et al. Xanthogranulomatous pyelonephritis: critical analysis of 30 patients. Int Urol Nephrol. 2011:43(1):15-22.

33. Guzzo TJ, Bivalacqua TJ, Pierorazio PM, Varkarakis J, Schaeffer EM, Allaf ME. Xanthogranulomatous pyelonephritis: presentation and management in the era of laparoscopy. BJU Int. 2009;104(9):1265-8.

34. Korkes F, Favoretto RL, Bróglio M, Silva CA, Castro MG, Perez MDC. Xanthogranulomatous pyelonephritis: clinical experience with 41 cases. Urology. 2008;71(2):178-80.
35. Loffroy R, Guiu B, Watfa J, Michel F, Cercueil JP, Krausé D. Xanthogranulomatous pyelonephritis in adults: clinical and radiological findings in diffuse and focal forms. Clin Radiol. 2007:62(9):884-90.

36. Vanderbrink BA, Ost MC, Rastinehad A, Anderson A, Badlani GH, Smith $A D$, et al. Laparoscopic versus open radical nephrectomy for xanthogranulomatous pyelonephritis: Contemporary outcomes analysis. J Endourol. 2007;21(1):65-70.

37. Kapoor R, Vijjan V, Singh K, Goyal R, Mandhani A, Dubey D, et al. Is laparoscopic nephrectomy the preferred approach in xanthogranulomatous pyelonephritis? Urology. 2006;68(5):952-5.

38. Rosoff JS, Raman JD, Del Pizzo JJ. Feasibility of laparoscopic approach in management of xanthogranulomatous pyelonephritis. Urology. 2006;68(4):711-4.

39. Nawaz H, Khan S, Hussain I, Ahmed S, Khan M, Niazi N. Xanthogranulomatous pyelonephritis due to calculi: report of 63 cases and review of literature. J Pak Med Assoc. 2005;55(9):387-9.

40. Saavedra Jo S, Pow-Sang Godoy M, Benavente Corrales V, Morante Deza C, Meza Montoya L, Taxa Rojas L, et al. Xanthogranulomatous pyelonephritis: clinical, radiological and pathologic characteristics. Arch Esp Urol. 2004:57(6):595-600.

41. Zorzos I, Moutzouris V, Korakianitis G, Katsou G. Analysis of 39 cases of xanthogranulomatous pyelonephritis with emphasis on CT findings. Scand J Urol Nephrol. 2003;37(4):342-7.

42. Bingöl-Koloğlu M, Ciftçi AO, Senocak ME, Tanyel FC, Karnak I, Büyükpamukçu N. Xanthogranulomatous pyelonephritis in children: diagnostic and therapeutic aspects. Eur J Pediatr Surg Off J Austrian Assoc Pediatr Surg. Zeitschrift fur Kinderchirurgie. 2002;12(1):42-8.

43. Samuel M, Duffy P, Capps S, Mouriquand P, Williams D, Ransley P. Xanthogranulomatous pyelonephritis in childhood. J Pediatr Surg. 2001;36(4):598-601.

44. Tiu CM, Chou YH, Chiou HJ, Lo CB, Yang JY, Chen KK, et al. Sonographic features of xanthogranulomatous pyelonephritis. J Clin Ultrasound. 2001;29(5):279-85.

45. Kim JC. US and CT findings of xanthogranulomatous pyelonephritis. Clin Imaging. 2001;25(2):118-21.

\section{Publisher's Note}

Springer Nature remains neutral with regard to jurisdictional claims in published maps and institutional affiliations.
Ready to submit your research? Choose BMC and benefit from:

- fast, convenient online submission

- thorough peer review by experienced researchers in your field

- rapid publication on acceptance

- support for research data, including large and complex data types

- gold Open Access which fosters wider collaboration and increased citations

- maximum visibility for your research: over $100 \mathrm{M}$ website views per year

At BMC, research is always in progress.

Learn more biomedcentral.com/submissions 